\title{
Valuing Environmental Resources: A Constructive Approach
}

\author{
ROBIN GREGORY, SARAH LICHTENSTEIN, AND PAUL SLOVIC \\ DECISION RESEARCH \\ 1201 OAK STREET \\ EUGENE, OREGON 97401
}

\begin{abstract}
The use of contingent valuation (CV) methods for estimating the economic value of environmental improvements and damages has increased significantly. However, doubts exist regarding the validity of the usual willingness to pay $\mathrm{CV}$ methods. In this paper we examine the $\mathrm{CV}$ approach in light of recent findings from behavioral decision research regarding the constructive nature of human preferences. We argue that a principal source of problems with conventional CV methods is that they impose unrealistic cognitive demands upon respondents. We propose a new $\mathrm{CV}$ approach, based on the valuestructuring capabilities of multiattribute utility theory and decision analysis, and discuss its advantages and disadvantages.
\end{abstract}

In press, Journal of Risk and Uncertainty

(minor revisions pending) 


\section{Introduction}

Contingent valuation (CV) has been used by economists to value public goods for about twenty-five years. The approach posits a hypothetical market for an unpriced good and asks individuals to state the dollar value they place on a proposed change in its quantity, quality, or access. Development of the $\mathrm{CV}$ concept has been described in reviews by Cummings, Brookshire, and Schulze (1986) and Mitchell and Carson (1989). The approach is now widely used to value many different goods whose quantity or quality might be affected by the decisions of a public agency or private developer. Environmental goods have received particular attention because they are highly valued by society and entail controversial tradeoffs (e.g., manufacturing costs vs. pollution, urban development vs. wetlands protection) but are not usually sold through markets (Bromley, 1986).

The visibility of CV methods ${ }^{1}$ has greatly increased following the 1989 interpretation of CERCLA (the Comprehensive Environmental Response, Compensation, and Liability Act of 1986) by the District of Columbia Circuit Court of Appeals (in Ohio v. United States Department of the Interior). This decision (a) granted equal standing to expressed and revealed preference evaluation techniques (with willingness to pay measures preferred in all cases), (b) accepted nonuse values as a legitimate component of total resource value, and (c) recognized a "distinct preference" in CERCLA for restoring damaged natural resources rather than simply compensating for the losses (Kopp, Portney, and Smith, 1990). The court's opinion on these three issues will likely lead to a substantial redrafting of the Department of Interior's rules for natural resource damage assessments. 
Interest in CV applications has given rise to much research. Recent studies, for example, have used CV to estimate the value of wetlands protection (Loomis, Hanemann, and Kanninen, 1991), water quality improvements (Desvousges, Smith, and Fisher, 1987), groundwater (Mitchell and Carson, 1989), and forest wildlife resources (Walsh et al., 1990). ${ }^{2}$ On the other hand, much has been written about problems with $\mathrm{CV}$ techniques: they capture attitudinal intentions rather than behavior (Ajzen and Peterson, 1988), important information is omitted from CV questionnaires (Fischhoff and Furby, 1988), and their results are susceptible to influence from cognitive and contextual biases (Brown and Slovic, 1988).

One response to these criticisms is to argue that $\mathrm{CV}$ methods can provide valid estimates of resource values if studies are done carefully. This is the position taken by many practitioners of CV methods (e.g., Brookshire and Coursey, 1987; Randall, Hoehn, and Brookshire, 1983). Several prominent critics of current CV methods also have argued for greater care in application; for example, Fischhoff and Furby (1988) provided detailed listings of the information needed to inform CV participants sufficiently about the assigned payment task, the social context for evaluation, and the good under consideration.

In contrast, others view these problems as casting doubt on the accuracy of $\mathrm{CV}$ responses and the usefulness of even the most carefully conducted $\mathrm{CV}$ results in litigation and damage assessments. Indeed, some reject $\mathrm{CV}$ as a method for obtaining monetary values of unpriced environmental goods. For example, Phillips and Zeckhauser (1989) questioned whether any CV study will be able to meet standard criteria of reliability and validity. 
Kahneman and Knetsch (1992) have argued that CV responses denote moral sentiments rather than economic values.

We believe there is a need for monetary assessments of environmental damages and that an evaluation approach based on individual's expressed preferences is appropriate for this purpose. However, we believe that the wholistic measures of monetary value used in current $\mathrm{CV}$ methods are flawed because they impose unrealistic cognitive demands upon respondents. In our view, improved methods for valuing nonmarket natural resources can be found by paying closer attention to the multidimensional nature of environmental values and to the constructive nature of human preferences (Gregory and McDaniels, 1987). The underlying assumption of the approach to be discussed in this paper is that people have strong feelings, beliefs, and values for many things that are not sold through markets (Brown, 1984). However, people's cognitive beliefs about these values typically are not numerically quantified and, most importantly for $\mathrm{CV}$, are not represented monetarily.

The fact that people are not used to thinking about environmental goods in monetary units suggests that a $\mathrm{CV}$ approach must function as a kind of tutorial, building the monetary value as it elicits it. We therefore view a $\mathrm{CV}$ survey as an active process of value construction (Tversky, Sattath, and Slovic, 1988) rather than as a neutral process of value discovery. Thus, we believe, the designers of a $\mathrm{CV}$ study should function not as archaeologists, carefully uncovering what is there, but as architects, working to build a defensible expression of value. 
reducing the risks from chemical products were higher when they were given paired comparisons (i.e., choices) than when they were asked to provide WTP values. Irwin et al. (in press) conducted several studies showing preference reversals in WTP. These studies involved comparisons of improvements in consumer goods, such as a better camera or a better VCR, with improvements in air quality. Their successful prediction of preference reversals, whereby WTP based on a single-stimulus response favored improvements in consumer goods and WTP based on a choice response favored improvements in air quality, was based on two judgment effects found in the decision-making literature: the compatibility effect (Slovic, Griffin, and Tversky, 1990), and the prominence effect (Tversky, Sattath, and Slovic, 1988).

Findings of preference reversals involving environmental values provide strong evidence for the constructive nature of preference. As Tversky, Sattath, and Slovic (1988) observed:

In the classical analysis, the relation of preference is inferred from observed responses and is assumed to reflect the decision maker's underlying utility or value. But if different elicitation procedures produce different orderings of options, how can preferences and values be defined? And in what sense do they exist? (p. 383)

The significance of changes in context on a person's expressed preferences supports this constructive view of values. For example, an attribute that would otherwise be of minor importance is more heavily weighted if all the objects are clearly described in terms of that attribute, when other attribute descriptions are incomplete (Slovic and McPhillamy, 1974). 
Huber (1980) showed that decision processes were influenced by whether information was presented in numerical or verbal form. Gaeth and Shanteau (1984) showed that inclusion of irrelevant information impaired judgment. Many context effects are grouped under the label framing effects (Hogarth, 1982; Tversky and Kahneman, 1981). For example, calling a sure loss "insurance" makes it more palatable (Slovic, Fischhoff, and Lichtenstein, 1982). Tversky and Kahneman's oft-cited "Asian disease" problem (1981) showed a reversal of preference when the wording of two public health problems was framed in terms of "saving lives" versus a "loss of life" framing.

Not all the research on context effects applies directly to CV. All, however (and we have cited only a sampling above), reinforces the view that people are not just reporting their values or preferences. Instead, they are constructing them, with whatever help or cues the circumstances provide.

The economists' prevailing response to preference construction is that wholistic measures of value can be trusted but separate values for components cannot (e.g., Freeman, 1989; Randall, 1986). Yet this view, that people can aggregate values but cannot partition them, flies in the face of the decision-making literature. This literature tells us that, when faced with complex values, people often resort to simplifying strategies; Payne, Bettman, and Johnson (1992) have oriented their extensive review around this theme. Moreover, simplifying strategies increase when the complexity of the stimuli increases (Johnson, Meyer, and Ghose, 1989). Studies have found that people typically are unaware of their simplications and that, when people are asked to make wholistic judgments about 
multidimensional stimuli, they typically make use of fewer cues than they say they do (Slovic and Lichtenstein, 1971). In short, the more complex a decision problem, the more likely that expressions of value will be constructed based on only a subset of the available information. Dawes (1977), for example, reviewed both this literature and the findings that simple combinations of judged parts accurately predict known wholes, and recommended just the opposite: trust the values obtained from decomposition procedures more than those obtained from wholistic judgments.

An important corollary of the constructive view is that the strong values that people hold for environmental goods are not represented in their minds in monetary form. Consider all the goods that we might want to value in dollar terms. These could be arrayed on a continuum according to the level of market experience that we have with them. At one extreme would be goods such as groceries, for which market experience is great and the strength of our values or preferences can be relatively easily represented by a market price. As we move from groceries to appliances, automobiles, and homes, market experience lessens and the ease of representing our preferences monetarily declines as well. For goods such as air or water quality, wilderness areas, endangered species, and many other elements of the natural environment, the market no longer applies and the link between values and money becomes tenuous-so tenuous that it may not exist. Thus, we can have strongly held values that are not at all coded mentally in terms of dollars. Attempts to translate such values into monetary equivalents must take special cognizance of this problem. 
One demonstration of the absence of a monetary representation for values comes from a study by Slovic, Lichtenstein, and Fischhoff (1979) that asked people to evaluate the social seriousness of a death from a specified cause (e.g., alcoholism, cancer) by equating that death with a monetary loss. This was done by asking the respondents to compare a death from each cause to a standard unit of loss to society. In one condition, this standard loss was $\$ 1,000,000$. In a second condition, with a new group of respondents, this standard loss was $\$ 10,000$. Respondents were asked to provide a multiplying or dividing factor to indicate how many times greater (or smaller) the specified death (e.g., a cancer death) was in comparison to the standard.

The geometric mean multipliers ranged in orderly fashion from smoking and alcoholcaused deaths at the low end, judged less serious than the standard, to death from pesticides and nuclear power accidents at the extreme high end of the distribution. However, the mean ratios were almost identical in the two groups, despite the 100 -fold difference in the comparison standard. For example, the geometric mean social cost for an alcohol-caused death was .91 for the $\$ 10^{6}$ standard and .89 for the $\$ 10^{4}$ standard. The correlation between the means in the two conditions, across 34 causes of death, was .94. In other words, the multiplying factors were almost perfectly consistent across the 34 items but the dollar values implied by the geometric means differed by a factor of 100 . Although there may be other explanations, these results can be interpreted as indicating that the seriousness of deaths from specified causes differed reliably across causes but was not represented monetarily in our respondents' minds. 
Valuing Environmental Resources

Gregory, Lichtenstein, \& Slovic/11

We believe that the absence of any monetary representation is a principal cause of the embedding (or part-whole) effect observed by both CV proponents (e.g., Mitchell and Carson, 1989) and critics (Kahneman and Knetsch, 1992), whereby the same good is assigned a lower value when it is inferred from WTP for a more inclusive good than if the good is evaluated on its own. For example, Kahneman and Knetsch report that the willingness of Toronto residents to pay to maintain fishing by cleaning up the lakes in a small area of Ontario was almost as great as their willingness to pay to maintain fishing in all Ontario lakes. They replicated this finding for a diverse set of public goods. Kahneman and Knetsch interpreted their findings as indicating that the "good" that subjects are willing to pay for in these studies is a "sense of moral satisfaction" which exhibits an embedding effect: the satisfaction associated with contributing to an inclusive cause extends with little loss to any significant subset of that cause. An alternative explanation is that the subjects in these studies had no well-defined monetary representation of value for the goods.

\section{Desirable Features of an Environmental Values Elicitation Approach}

What are the characteristics of a good, defensible method for eliciting environmental values? The ultimate criterion is validity: a method clearly measures only what it's supposed to measure. In a classic paper, Cronbach and Meehl (1955) discussed four types of validity, of which three are relevant to CV methods: predictive, concurrent, and constructive validity ${ }^{3}$. Predictive and concurrent validity refer to the close relationships between the measure and a criterion of known validity (they differ only in timing: predictive validity 
involves comparison with a future criterion; concurrent validity involves a present criterion). Economic theory posits just such a criterion of known validity: unrestrained market prices at equilibrium. Unfortunately, CV methods are intended for use precisely in those situations for which no market exists.

Construct validity is thus the concept underlying tests of CV's validity. "A construct is defined implicitly by a network of associations or propositions in which it occurs . . . Construct validation is possible only when some of the statements in the network lead to predicted relations among observables" (Cronbach and Meehl, pp. 299-300). Economic theory, in which the construct of contingent valuation is embedded, generously satisfies these requirements.

Construct validity is not sought via one definitive study but in the integration of evidence from many different sources. The finding that $\mathrm{CV}$ methods roughly match market values when they are applied, experimentally, to situations in which market values exist (Bishop and Heberlein, 1979; Dickie, Fisher, and Gerking, 1987) is one such piece of evidence favoring construct validity. Other evidence comes from comparisons of different resource-assessment methods, such as comparing direct WTP with travel cost or hedonic (indirect) methods (e.g., Brookshire, Thayer, Schulze, and d'Arge, 1982; Smith, Desvousges, and Fisher, 1986). Such studies have shown agreement among measures within a range of about $+/-50 \%$ (Cummings, Brookshire, and Schulze, 1986). Although a 50\% margin of error might appall a polluter presented with a bill for damages under CERCLA, such findings do help to build the case for construct validity. 
But construct validity also requires negative findings. If the method is valid, variables that should not affect the results do not. Here conventional $\mathrm{CV}$ methods fare poorly. First, there is a widely observed disparity between the maximum amount that people are willing to pay to acquire a good and the minimum amount they are willing to accept (WTA) to give it up. The observed difference between WTP and WTA is not, as economic theory would predict, small (most persuasively shown by Kahneman, Knetsch, and Thaler, 1990; see also Bishop and Heberlein, 1979; Knetsch and Sinden, 1984). Moreover, as noted earlier, the change from a WTP to a choice response mode induces reversals in the preference ordering of an environmental improvement versus a market-commodity improvement (Irwin et al., in press). Such findings contradict economic theory and thus seriously threaten the construct validity of WTP-based CV methods.

We are not surprised by these validity-threatening findings, for underlying the search for validity are the assumptions that monetary values for nonmarket goods really do exist and researchers can find appropriate ways to measure them. In contrast, we hold that such values do not exist in monetary form. Instead, they are created during the elicitation process. Thus value formation is intimately tied to the specifics of the elicitation procedures. Following Simon's well-known distinction between procedural and substantive rationality (1978), we therefore present five process criteria that, if satisfied, can be used to defend the goodness of a CV method. 


\section{Criterion 1: Accommodate the Multidimensionality of Value}

There is a robust basis, in both economics and decision theory, for the perspective that people conceptualize goods in multidimensional terms (Keeney and Raiffa, 1976; Lancaster, 1966). This is surely true for environmental goods, as symbolized by the "multiple use" concept that guides the resource-management policies of federal agencies such as the U.S. Forest Service. Bishop (1986) presents categories of economic benefits from the environment that include both consumptive and nonconsumptive user benefits as well as several classes of nonuser values. Environmental philosophers (e.g., Ralston, 1981) have distinguished a large number of dimensions that can be used to characterize environmental goods, including scientific, aesthetic, biodiversity, religious, symbolic, and life-support values in addition to economic and recreational values.

The complexity and multidimensionality of environmental values means that a value elicitation method must be sensitive to this diversity of values. Yet a good CV method also must recognize the difficulties people have in thinking about such complexities. The experimental evidence previously described indicates that even when all aspects of all alternatives are fully described, people find it difficult to make explicit tradeoffs and typically rely on cognitive strategies that result in discounting or neglecting some important aspects.

The typical CV task goes one step further: a wholistic response is requested for a single stimulus presented without either an explicit listing of the relevant dimensions of value or a description of the stimulus on each dimension. Because what is out of sight may be out of mind (Fischhoff, Slovic, and Lichtenstein, 1978), this situation can be expected to lead to 
the greatest distortions in the expression of multidimensional values. Gregory, MacGregor, and Lichtenstein (1992) have shown that open-ended, wholistic WTP responses were poorly correlated, across a number of market and nonmarket goods, with several value-relevant attributes. Is this so surprising? In most elicitation settings, people have had no experience in thinking about the structure-the multiple dimensions or attributes - of their values. How can people think clearly about the big picture when they cannot distinguish clearly among the components?

We realize that some $\mathrm{CV}$ studies include information about the attributes of the good under consideration. For example, some CV booklets extensively describe a proposed project. Others present two possible projects, described not only in text but also in a pairedcomparison chart of attributes (thus aiding the respondent to make a richer consideration). However, even these enhanced booklets describe facts and attributes of facts, rather than attributes of value. A good $\mathrm{CV}$ method requires not only the fostering of tradeoffs among many attributes but prior exploration to determine what attributes matter to people, so that the situation can be described in terms of these attributes.

\section{Criterion 2: Minimize Response Refusals}

Response refusals are a common problem in CV studies (Mitchell and Carson, 1989). Irwin et al. (1990), for example, reported that 35 percent of respondents either refused to provide a WTP response or reported zero WTP while reporting, on other scales, strong values for a proposed air-quality improvement. Elegant methods have been proposed for 
estimating the missing WTP values. However, a better CV approach should avoid this vexing problem. We believe this can be achieved by asking respondents for an expression of monetary value rather than for their willingness to pay.

\section{Criterion 3: Exclude Irrelevancies}

If a CV study were intended to predict, for example, the results of a public vote on funding for a project, then any attribute value that will affect how people vote should properly be expressed in the study. However, contingent valuations are often needed for situations in which some aspects of value, even if strongly held, are legally or ethically irrelevant. For example, we conjecture that an individuals' willingness to pay to restore a damaged habitat or her willingness to accept compensation for an environmental loss will be strongly affected by the source of the damage (e.g., a natural cause vs. a careless spill by a detested chemical company). Legally, however, this attribute (who's to blame) is irrelevant under CERCLA. A good CV method should allow the exclusion of such attributes. This is difficult, if not impossible, for wholistic response methods like WTP or WTA.

\section{Criterion 4: Separate Facts from Values}

Defensible measures of value require respondents who have knowledge of the good under consideration as well as knowledge of their preferences with regard to the good. For simple goods or for activities with which people have extensive experience, it makes sense to assume that the respondents are competent to assess both facts and values. However, many 
of the proposed environmental changes that form the subject of CV studies are scientifically complex. In such cases, a good $\mathrm{CV}$ method should not require that respondents have a thorough understanding of the scientific complexities in order to express their preferences.

Consider the CV prescriptions advocated by Fischhoff and Furby (1988). They identify three types of information-relating to the good, the payment vehicle, and the social context-that should be provided to all respondents in a CV survey, thereby making everyone an expert. We agree that achievement of these criteria would lead to improved value estimates. However, we also believe that this approach is impractical if it is taken seriously because people are not experts in technical matters nor even good learners of technical information. ${ }^{4}$

\section{Criterion 5: Ask the Right Question}

The usual CV study asks a WTP question, such as "How much would you be willing to pay each year in higher prices or increased taxes for . . ?" or "Would you be willing to pay $\$ \mathrm{X}$ each year in higher prices or increased taxes for ... ?" (with \$X varied across respondents). Questions based on willingness to accept (WTA) payment for some loss are less common, because refusal rates are considerably higher and because average responses seem unduly large (Cummings, Brookshire, and Schulze, 1986; Kahneman, Knetsch, and Thaler, 1990).

Consider the case where a factory discharges pollutants into a lake, causing environmental damage. The relevant question under CERCLA is: How much should the 
damager pay? The general answer is that the damager is required under CERCLA to pay that amount necessary to restore or replace the lost resources (Kopp, Portney, and Smith, 1990). Let us suppose that this is done to the extent reasonably possible, but that the repair takes some time and is not complete. Then the damager is liable both for losses from the time the damage occurs until the time the repair (whether by nature or by humans) is finished and for losses that cannot be repaired. How should a CV study assess the value of these losses?

This is a typical question and an important one for environmental policy analysis. However, WTP or WTA seems to us inappropriate for this question because it is not the responsibility of the respondent to pay for the damage. There are two separate points here. First, the request to pay for damages to the natural environment brings up the question of an individual's entitlement. If ownership of the resource (e.g., good water quality) forms part of a people's status quo assets, then why should they pay for what they already have a right to? The appropriate response is a refusal to pay. Second, under CERCLA, payment is the responsibility of the damager. Clearly, for some types of environmental damage, such as a widespread degradation of water quality caused by many damagers, the responsibility may effectively fall upon us all: whether we like it or not, consumer prices or taxes will pay for the clean up. But even in such cases, it is likely that many people will deny the responsibility. This denial seems to underlie the large percentage of refusals in many $\mathrm{CV}$ studies of damaged resources. 
In the factory discharge considered here the damager is clearly liable. Thus we must consider WTA. However, if you, the respondent, ask for too much money-so that your demand is refused-what will happen? The essence of any WTP or WTA question is a tradeoff of some sort between money and a good. But here we are evaluating unrestorable losses. If you are not paid, there will still be a loss: there is no compensating event in the no-exchange alternative that provides a balance against which you can weigh your WTA. Lacking such restraint, why not go for the moon?

It is tempting, in such cases, to ask a different question such as "How much would you pay to avoid a future spill like this one?" But this is, indeed, the wrong question, not only because it denies the true structure of the problem but also because the respondents are thereby limited by their own ability to pay although the real situation depends, instead, upon the damager's ability to pay.

We have now trapped ourselves inside an uncomfortable box. WTP forms of CV questions are inappropriate for CERCLA cases because they lack the proper structure. WTA forms of $\mathrm{CV}$ questions are inappropriate for practical reasons. The usual way out of this conundrum for $\mathrm{CV}$ practitioners is to employ WTP questions anyway, perhaps with an apology. However, this apologetic stance strikes us as unfortunate because there is no reason why any measure of people's WTP needs to be obtained directly. Rather, what needs to be known for purposes of CERCLA is the monetary value people place on the damaged good. This brings us to the central argument for a new approach to eliciting values for environmental resources. If values are constructed during the elicitation process in a way 
that is strongly determined by context and has profound effects on the resultant evaluations, we should take a deliberate approach to value construction in a manner designed to rationalize the process.

\section{Using Multiattribute Utility Theory in Resource Valuations}

We believe that there already exists a sound, formal approach to value construction that can provide the basis for an improved CV method. This approach draws on the techniques and practices of multiattribute utility theory.

Multiattribute utility theory (MAUT) underlies the practice of decision analysis and specifies, axiomatically, the conditions under which one can sensibly attach numbers to values. MAUT and decision analysis are systematic procedures designed to assist people in making choices in the presence of conflicting objectives and uncertainty. They are "a formalization of common sense for decision problems that are too complex for informal use of common sense" (Keeney, 1982). Detailed descriptions of MAUT and decision analysis are given by Keeney (1980) and by von Winterfeldt and Edwards (1986).

MAUT is essentially a set of axiomatic theories of preference (Keeney and Raiffa, 1976). The central theorem of each theory says that if people can make choices based on their preferences and if these choices satisfy the axioms, then one can (a) assign numbers to utilities or values (we will use these terms as synonymous) and (b) specify a rule for combining the numbers into a summary measure such that an object with a larger summary measure is preferred over an object with a smaller summary measure. The measurement 
scale underlying these utilities is not cardinal; it does not have an invariant zero point. But it is stronger than ordinal because the ordering of differences between the measures, as well as the ordering of the measures, is invariant. Psychologists call such a scale an interval scale (Stevens, 1951).

The most helpful aspect of decision analysis is its ability to formally express subjective judgments in the assessment of alternatives and to establish an explicit framework for integrating the multidimensional components of complex values. However, some further development of these techniques will be needed to use decision analysis as the basis for improvements in CV methods. This is because the purpose of MAUT and decision analysis is to promote insight to help decision makers make choices among alternative plans of action. The purpose of a MAUT-based approach to $\mathrm{CV}$ would be more specific: to provide dollarbased evaluations of specific nonmarket goods or programs.

\section{A. Proposed Approach}

The general approach required in a multiattribute CV (MAUT/CV) analysis can be described as a sequence of four steps.

\section{Structure the Problem}

In this step the analyst collects, lists, and organizes a description of the problem, identifying all the attributes (that is, all the aspects of the problem that have value to people). The goal is to develop an explicit, comprehensive picture of all factors that contribute 
significantly to the value of the good or activity. To do so, the analyst will consult both technical experts, to get the facts, and the affected citizenry, to find the link between the facts and the values.

This structuring process differs in two respects from the usual practice of CV. First, the value attributes are made explicit. The usual CV study, in contrast, describes the situation to be evaluated without such an explicit listing. The respondent is assumed to know all attributes of value or to infer them from descriptions in the questionnaire booklet. Second, a MAUT/CV would rely on the affected citizenry to elucidate the attributes of value. This step, which precedes the elicitation of values, is typically omitted in CV. The value attributes implicit in the usual CV study come from experts in the topic of concern or from the study authors, rather than directly from the affected citizenry.

In a MAUT/CV diverse groups of people should be consulted to select the value attributes. These stakeholders are defined in an operational sense as groups of people who, for any reason (e.g., place of residence, occupation, favored activities), share common values or opinions regarding a proposed action (Edwards and von Winterfeldt, 1987). The MAUT/CV analyst might convene three to ten stakeholder groups, each composed of three to seven people; from each group a values structure is elicited. Careful selection of stakeholder groups ensures that the full range of views is adequately covered. For example, the representatives of an environmental advocacy organization might be expected to present a somewhat different list of attributes than would members of the local Chamber of 
Commerce, but the views of these two groups are likely to encompass those of many other citizens.

In a complex problem, the expressed attributes will vary in level of generality and therefore often can be structured hierarchically into a value "tree." The eventual goal is to find a single hierarchy of values that all the shareholders can agree is complete. This values hierarchy must also be built with due concern for the form of the utility combination rule. The simplest such rule is additive; one adds all the utilities of the lowest-level scales to find the total utility. This combination rule requires value independence: the value of one level of one attribute must not depend upon what the levels are on the other attributes. The decision analyst must probe frequently for value independence; lack of independence may signal an additional, unreported attribute of value.

The finished values hierarchy may have components using causal models, economic models, influence or means-ends diagrams, and so forth showing the linkages between specific measures at the bottom and the abstract attributes at the top. Depending on the situation, some components may have probabilities explicitly built into the model, so that the final utility calculation will be an expected utility.

Suppose that someone wanted to do a MAUT/CV study of the monetary value of the damage resulting from a specific pollutant dumped into Lake Michigan. Technical experts can provide information describing the lake before and after the damage. These descriptions then can be presented to representatives of the people affected by the damage to identify the value attributes. For example, the physical event of the death of a large number of fish 
might imply aesthetic loss (when the dead fish wash up on the shore), loss of genetic diversity, and loss of commercial fishing jobs and profits; these losses indicate the value attributes.

Generic attributes for the lake problem might be Effects on Scenic Beauty, Effects on Genetic Diversity, Human Health Effects, Effects on Commerce, and so forth. Each attribute would have sub-attributes; for example, sub-attributes influencing Effects on Commerce might be Real Estate Values (the price of vacation homes would go down if the shore line becomes ugly), Tourist Values, and Entitlement (expressing the general public's non-use value for a beautiful lake). Some or all of these sub-attributes might be further broken down into sub-sub-attributes, and so forth until all relevant values have been listed and organized. At the lowest level each attribute is described in terms of some specific measure. For example, one sub-component of Scenic Beauty concerned with shore-line attractiveness might have as its bottom-level measure the number of dead fish per acre of beach.

\section{Assess Utilities}

A typical CV study elicits values from a random sample of the affected citizenry; WTP responses are given by hundreds or thousands of people. In contrast, an approach based in decision analysis would elicit utilities (values) from the stakeholder groups, less than 100 people. Depth of value analysis is substituted for breadth of population sampling. 
Utilities are assessed for every lowest-level value scale. To start with, it is convenient to assess every utility on a common scale, say, from 0 to 100 . For example, the maximum number of dead fish per acre on Lake Michigan beaches as a result of our hypothetical pollutant spill might be assigned a utility score of 100 and the minimum impact level, perhaps 0 dead fish per acre, would be assigned a score of 0 . It is essential that this range of outcomes be carefully specified, that the range encompass all reasonably possible values for the attribute measure, and that this range, once chosen, remain fixed throughout the analysis. Tradeoffs are then assessed, using weights or multiplicative factors-that rescale the utilities in recognition that not all attributes of value are equally important.

All these value elicitations would be done with numerous consistency checks. If you have told the analyst that a change from 0 to 100 on scale $A$ is twice as good as a change from 0 to 100 on scale B and that a change from 0 to 100 on scale B is four times as good as such a change on scale $\mathrm{C}$, the analyst will then check to see that you do, indeed, believe that the scale A change is eight times as good as the scale $\mathrm{C}$ change.

\section{Calculate the Total Value}

Once all the pieces are in place, the combination rule specifies how to calculate the total utility for any particular plan, program, or scenario. This total utility will be expressed using a single arbitrary "utile" unit of measurement. For contingent valuation, these units must be converted to dollars. In theory, this conversion need only be made at one place in the model. For example, one such conversion might be made in the Lake Michigan pollution 
example by noting the monetary value and the utility (or, here, disutility) of the loss of one ton of fish to one fishery. Because all utilities, including this one, are measured on a common scale, the monetary worth of all utilities, including the total utility, can be computed from this one conversion. In practice, of course, one would want to find several parts of the model for which both utilities and their monetary equivalents are known (e.g., real estate values, perhaps even the value of a life).

\section{Perform Sensitivity Analysis}

The final step required in performing a MAUT/CV analysis would be to recalculate the final utility, using variations in the utilities and tradeoffs, to see how sensitive the final answer is to such variations (Merkhofer and Keeney, 1987). Sensitivity analyses performed on a first-draft MAUT/CV might be used to show which aspects should, because of their strong effect upon the total, be subjected to additional stakeholder elicitations or to largescale sampling of public values.

Different stakeholder groups can be expected to produce different utilities and tradeoffs; thus, the total monetary value may differ across groups. Sensitivity analysis will reveal the most important causes of these disagreements. The analyst can then return to each of the stakeholder groups to explore the possibility that small changes in their utilities and tradeoffs would be acceptable to the group yet produce a total value more similar to the total value calculated for other groups. Although there is some encouraging evidence (Gardiner and Edwards, 1975) that the use of MAUT diminishes the disagreement between highly 
polarized groups, further research is needed to explore the conditions under which a single monetary value can be found that adequately expresses the values of all stakeholders.

\section{B. Advantages and Disadvantages of MAUT/CV}

The linkage of MAUT to contingent-valuation approaches will not be an all-purpose panacea. However, we believe that use of a MAUT-based approach to CV offers some strong advantages and possible solutions to several of the most troubling problems confronting environmental researchers. We start by discussing MAUT/CV in terms of the five evaluative criteria discussed above. We then comment on other advantages and disadvantages of a multiattribute $\mathrm{CV}$ approach.

\section{Accommodates the Multidimensionality of Value}

The judgments required as inputs to a MAUT/CV model will not be easy ones to make. But they are not wholistic judgments requiring the simultaneous integration of many dimensions of value. Thus, it is less likely that important aspects of value will be lost because of cognitive overload. Most importantly, the values that guide a MAUT/CV study will be elicited from a wide range of the potentially affected stakeholders. These stakeholders have a right to express their values as part of an open, constructive decision-aiding process. In contrast, the values that guide a conventional $\mathrm{CV}$ study are those of the experts-be they economists, psychologists, or lawyers-who have been asked to write the CV questionnaire. 
We believe this to be an inferior process, because in the absence of early stakeholder involvement it is easy for important values to be neglected or mispecified.

\section{Minimizes Response Refusals}

MAUT measures value without regard to the problem of who must pay, an issue that can be decided in the voting booth or by the courts. To the extent that this problem underlies response refusals, a multiattribute $\mathrm{CV}$ procedure should reduce or eliminate the problem.

One obstacle to incorporating MAUT techniques is an ethical concern, stemming from the quantification of utilities for various goods and activities. Recognizing distinctions among value components and putting numbers on values is not easy and, to some members of the public, it may be repugnant (MacGregor and Slovic, 1986). The argument can be made that the assignment of numerical values only makes clear the trade-offs that otherwise still would be made implicitly rather than explicitly. For some this logic will be soothing; for others, however, any process requiring quantification is likely to remain questionable. A further source of response refusals may arise from the extreme stances taken by different groups of stakeholders in a politically potent $\mathrm{CV}$ situation. Some stakeholder groups may refuse to participate for political or strategic reasons or because they distrust the agency conducting the study. In such situations, success may rest on the analyst's ability to convince respondents that cooperation in expressing their values will have a genuine impact on the results and that response refusals unfortunately may lead to the omission of their point of view. 


\section{Excludes Irrelevancies}

A MAUT/CV model would explicitly list the sources of value. Thus, a MAUT-based CV approach would address the real issues in the problem and permit in-depth examination of the factual and values bases for concern. If irrelevant attributes are proposed in the problemstructuring stage, the analyst can either exclude them from the model completely or include them as separate aspects whose effects on the total value can later be calculated.

\section{Separates Facts from Values}

Conducting a multiattribute $\mathrm{CV}$ study requires extensive knowledge about the facts of a problem and detailed elicitations of people's values. But the method allows the analyst to distinguish facts from values; stakeholders are asked to determine the components of value; experts then make the factual contributions to understand impact pathways and magnitudes. Thus, the people whose values are sought do not need to understand scientific complexities in order to express their values. Instead, their values are expressed in numerous pieces with each piece selected to be a readily understandable measure.

\section{Asks the Right Question}

There are many occasions when the financial ability of a population of people provides an appropriate and sensible limit on their willingness to pay and thus on their contingent valuation for some situation. This occurs, for example, when tax monies will be dedicated to a specific project. But often people's ability to pay is irrelevant to the contingent valuation 
problem. One prominent example is CERCLA cases, in which the goal of the valuation enterprise is to determine the monetary payment that must be made by a polluter. Here, MAUT has a distinct advantage in avoiding willingness to pay as a measure of value; it asks the right question: How valuable is this?

\section{Other Advantages and Disadvantages}

Integrates market and nonmarket values. Neither values for which extensive, competitive markets exist nor diffuse, vague, but strongly-held nonmarket values get an advantage in a MAUT model. Economic models can be subsumed into the model where appropriate. Explicit and simple measures can be sought for vague and diffuse nonmarket values. The strength of the approach is that the model can integrate these different kinds of value.

Lessens the embedding problem. There may be several causes of the embedding problem. Earlier in this paper we suggested that the absence of a monetary representation for a good may be a principal reason for embedding. In this case, the use of a MAUT-based approach to CV should help because it will assist people to structure their monetary values in a defensible manner. It also may be, as Kahneman and Knetsch (1992) suggest, that people are not really responding to the specific problem but are reporting a general willingness to donate money to good causes. Because spending money is not directly the focus of MAUT elicitations, this source of embedding would not occur. 
Alternatively, people may be trying to respond to the given problem but are unable to be sufficiently sensitive to its specifications (e.g., 2,000 dead fish, not 4,000 dead fish) because of its complexity. Two characteristics of a MAUT/CV method should increase such sensitivity. First, MAUT elicitation methods are decompositional and therefore do not require people to juggle many aspects of value at the same time. Second, the utility for each attribute is elicited across an entire range; respondents are, for example, asked to provide scale values separately for 2,000 fish and for 4,000 fish. It is hardly credible that in such a situation the respondents would give the same utility regardless of the number.

Irwin et al. (1990) have described another form of the embedding problem that seems to derive from people's beliefs about non-independence. They report approximately the same WTP for health improvements due to cleaner air, visibility improvements, and all improvements, apparently because the respondents assumed that any air cleaning leading to better health inevitably would also lead to better visibility, even though the researchers didn't mention it. In the MAUT method, such beliefs about non-independence would be discovered in the structuring stage; the model would be adjusted to accommodate them.

Flexible in changing circumstances. A MAUT/CV model would elicit a broad range of values for each attribute. As a result, the information is available so that the calculations can be redone if the circumstances change. Changing circumstances that add new elements to the problem, of course, will require further modeling and new elicitations. But in most cases such changes will involve a small portion of the whole analysis, most of which will not need re-doing. 
Suitable for construction. We have presented the view that people have not formed monetary values for many complex, nonmarket goods such as environmental improvements. Thus a successful $\mathrm{CV}$ method should help the respondents to think carefully and thoroughly about what they value in order to form their values. A MAUT/CV approach would provide the setting for such extensive consideration, in both its structuring and its valuing phases.

Every value elicitation method affects the values being elicited. So a MAUT-based method surely will. We cannot know the exact effects it would exert on people's values. But the process and results of a MAUT/CV would be explicitly recorded and thus open to scrutiny. In contrast to a WTP or a WTA study, one would be far less troubled by wondering what the respondents were and were not taking into consideration when expressing their values.

Cost. As far as we know, MAUT never has been used for contingent valuation of environmental resources. The first few exemplars might cost more than WTP studies now do because MAUT techniques would have to be adjusted and developed to meet $\mathrm{CV}$ applications whereas WTP techniques already have been extensively developed. After that, we don't know. A related concern derives from the required expertise: a MAUT/CV analysis would require the analyst to participate in the entire elicitation procedure with each stakeholder group. One of the criticisms often leveled at MAUT techniques is that their application requires as much art as science at a time when resources are scarce and there are few accomplished practitioners. However, the practice of a MAUT/CV effort strikes us as 
Valuing Environmental Resources

Gregory, Lichtenstein, \& Slovic / 33

no more demanding or subjective than the practice of conventional $\mathrm{CV}$ or, for that matter, cost-benefit analysis (Gregory, Keeney, and von Winterfeldt, 1992).

\section{v. Conclusion}

Recent evidence from behavioral decision research casts a perspective on contextual effects that goes beyond bias and challenges traditional views of the nature and stability of environmental preferences and values. According to this view, preferences and values for objects that are unfamiliar and complex are often constructed, rather than revealed, in the elicitation process.

We believe that the concept of constructed preferences has important implications for the dollar-based measurement of environmental values. Environmental resources typically are complex goods that are valued across a number of diverse dimensions and that have not been thought about in quantitative terms, let alone dollar terms. Wholistic measures of monetary value, as have been used in most $\mathrm{CV}$ studies, ignore these cognitive realities and require people to engage in a task that exceeds their capabilities. We propose that practitioners, rather than giving up on the attempt, adopt explicit value-structuring techniques that will link $\mathrm{CV}$ efforts with multiattribute utility theory and decision analysis. This new $\mathrm{CV}$ method has the potential to eliminate many of the most vexing problems of conventional $\mathrm{CV}$ approaches and provide defensible monetary measures of environmental values. 
Valuing Environmental Resources

Gregory, Lichtenstein, \& Slovic / 34

\section{References}

Ajzen, Icek, and George L. Peterson. (1988). "Contingent value measurement: the price of everything and the value of nothing?" In George L. Peterson, B. L. Driver, and Robin Gregory (ed.), Amenity resource valuation: integrating economics with other disciplines. State College, PA: Venture, 65-76.

Bishop, Richard. (1986). "Resource valuation under uncertainty: theoretical principles for empirical research." In Advances in applied micro-economics, vol. 4. JAI Press, Inc., 133-152.

Bishop, Richard, and Thomas Heberlein. (1979). "Measuring values of extramarket goods: are indirect measures biased?," American Journal of Agricultural Economics 61, 926930.

Bromley, Daniel. (ed.) (1986). Natural resource economics: policy problems and contemporary analysis. Boston, Massachusetts: Kluwer, Nighoff Publishing.

Brookshire, David S., and Donald Coursey. (1987). "Measuring the value of a public good: An empirical comparison of elicitation procedures, "American Economic Review 77, 554-566.

Brookshire, David S., Mark Thayer, William D. Schulze, and Ralph d'Arge. (1982).

"Valuing economic goods: a comparison of survey and hedonic approaches," American Economic Review 72, 165-177.

Brown, Thomas C. (1984). "The concept of value in resource allocation," Land Economics 60, 231-246.

Brown, Thomas C., and Paul Slovic. (1988). "Effects of context on economic measures of value." In George L. Peterson, B. L. Driver, and Robin Gregory (ed.), Integrating economic and psychological knowledge in valuations of public amenity resources. State College, PA: Venture, 23-30.

Cronbach, Lee J., and Paul M. Meehl. (1955). "Construct validity in psychological tests," Psychological Bulletin 52, 281-302.

Cummings, Ronald G., David S. Brookshire, and William D. Schulze. (1986). Valuing environmental goods: Assessment of the contingent valuation method. Totowa, New Jersey: Rowman and Allanheld. 
Valuing Environmental Resources

Gregory, Lichtenstein, \& Slovic / 35

Dawes, Robyn M. (1977). "Predictive models as a guide to preference," IEEE Transactions on Systems, Man and Cybernetics SMC-7, 355-358.

Desvousges, William, V. K. Smith, and Anthony Fisher. (1987). "Option price estimates for water quality improvements: A contingent valuation study for the Monongahela River," Journal of Environmental Economics and Management 14, 248-267.

Dickie, Mark, Ann Fisher, and Shelby Gerking. (1987). "Market transactions and hypothetical demand data: A comparative study," Journal of the American Statistical Association 82, 69-75.

Edwards, Ward. (1954). "The theory of decision making," Psychological Bulletin 51, 380417.

Edwards, Ward. (1961). "Behavioral decision theory," Annual Review of Psychology 12, 473-498.

Edwards, Ward, and Detlof von Winterfeldt. (1987). "Public values in risk debates," Risk Analysis 7, 141-158.

Einhorn, Hillel J., and Robin M. Hogarth. (1981). "Behavioral decision theory: processes of judgment and choice," Annual Review of Psychology 32, 53-88.

Fischhoff, Baruch, and Lita Furby. (1988). "Measuring values: a conceptual framework for interpreting transactions with special reference to contingent valuation of visibility," Journal of Risk and Uncertainty 1, 147-184.

Fischhoff, Baruch, Paul Slovic, and Sarah Lichtenstein. (1978). "Fault trees: sensitivity of estimated failure probabilities to problem representation," Journal of Experimental Psychology: Human Perception and Performance 4, 330-344.

Freeman, Myrick A. (1989). "Nonuse values in natural resource damage assessments." draft manuscript, In Ray Kopp, and V. Kerry Smith (ed.), Valuing natural assets: The economics of natural resource damage assessments. Washington, DC: Resources for the Future.

Gaeth, Gary J., and James Shanteau. (1984). "Reducing the influence of irrelevant information on experienced decision makers," Organizational Behavior and Human Performance 33, 263-282. 
Gardiner, Peter C., and Ward Edwards. (1975). "Public values: Multiattribute-utility measurement for social decision making." In M. F. Kaplan, and S. Schwartz (ed.), Human judgment and decision processes. New York: Academic, 1-37.

Gregory, Robin, Ralph L. Keeney, and Detlof von Winterfeldt. (1992). "Adapting the environmental impact statement process to inform decision makers," Journal of Policy Analysis and Management 11, 58-75.

Gregory, Robin, Donald MacGregor, and Sarah Lichtenstein. (1992). "Assessing the quality of expressed preference measures of value," Journal of Economic Behavior and Organization 17, 277-292.

Gregory, Robin, and Tim McDaniels. (1987). "Valuing environmental losses: What promise does the right measure hold?," Policy Sciences 20, 11-26.

Grether, David M., and Charles R. Plott. (1979). "Economic theory of choice and the preference reversal phenomenon," American Economic Review 69, 623-638.

Hogarth, Robin. (ed.) (1982). New directions for methodology of social and behavioral science: Question framing and response consistency. San Francisco: Jossey-Bass.

Huber, Oswald. (1980). "The influence of some task variables on cognitive operations in an information-processing decision model," Acta Psychologica 45, 187-196.

Irwin, Julie R., Douglas Schenk, Gary H. McClelland, William D. Schulze, Thomas Stewart, and Mark Thayer. (1990). "Urban visibility: some experiments on the contingent valuation method." In C. V. Mathei (ed.), Visibility and fine particles. Pittsburgh, PA: Air and Waste Management Association, 647-658.

Irwin, Julie R., Paul Slovic, Sarah Lichtenstein, and Gary H. McClelland. (In press). "Preference reversals and the measurement of environmental values," Journal of Risk and Uncertainty.

Johnson, Eric J., Robert M. Meyer, and Sanjoy Ghose. (1989). "When choice models fail: compensatory representations in negatively correlated environments," Journal of Marketing Research 26, 255-270.

Jones-Lee, Michael, Mark Hammerton, and Richard Phillips. (1985). "The value of safety: Results from a national survey," Economic Journal 95, 49-72.

Kahneman, Daniel, and Jack Knetsch. (1992). "Valuing public goods: The purchase of moral satisfaction," Journal of Environmental Economics and Management 22, 57-70. 
Kahneman, Daniel, Jack L. Knetsch, and Richard H. Thaler. (1990). "Experimental tests of the endowment effect and the Coase Theorem," Journal of Political Economy 98, 1325-1348.

Kahneman, Daniel, Paul Slovic, and Amos Tversky. (Eds.) (1982). Judgment under uncertainty: Heuristics and biases. New York: Cambridge University Press.

Keeney, Ralph L. (1980). Siting energy facilities. New York: Academic.

Keeney, Ralph L. (1982). "Decision analysis: An overview," Operations Research 30, 803- . 838.

Keeney, Ralph L., and Howard Raiffa. (1976). Decisions with multiple objectives. New York: Wiley.

Knetsch, Jack, and Jack Sinden. (1984). "Willingess to pay and compensation demanded," Quarterly Journal of Economics 99, 507-521.

Kopp, Raymond, Paul Portney, and V. Kerry Smith. (1990). "Natural resource damages: The economics have shifted after Ohio v. United States Department of the Interior," Environmental Law Reporter 4, 10127-10131.

Lancaster, Kelvin. (1966). "A new approach to consumer theory," Journal of Political Economy 74, 132-157.

Lichtenstein, Sarah, and Paul Slovic. (1971). "Reversals of preference between bids and choices in gambling decisions," Journal of Experimental Psychology 89, 46-55.

Loomis, John B., Michael Hanemann, and Barbara Kanninen. (1991). "Willingness to pay to protect wetlands and reduce wildlife contamination from agricultural drainage." In A. Dinar, and D. Zilberman (ed.), The economics and management of water and drainage in agriculture. Boston: Kluwer Academic.

MacGregor, Donald, and Paul Slovic. (1986). "Perceived acceptance of risk analysis as a decision-making approach," Risk Analysis 6, 245-256.

Merkhofer, M. W., and Ralph L. Keeney. (1987). "A multiattribute utility analysis of alternative sites for the disposal of nuclear waste," Risk Analysis 7, 173-194.

Mitchell, Robert C., and Richard T. Carson. (1989). Using surveys to value public goods: the contingent valuation method. Washington, DC: Resources for the Future. 
Payne, John W., James R. Bettman, and Eric J. Johnson. (1992). "Behavioral decision research: A constructive processing perspective," Annual Review of Psychology 43, 87-132.

Phillips, Carl, and Richard Zeckhauser. (1989). "Contingent valuation of damage to natural resources: How accurate? How appropriate?," Toxics Law Reporter, October 4, 520529.

Ralston, Holmes. (1981). "Values in nature," Environmental Ethics 3, 115-128.

Randall, Alan. (1986). "Valuation in a policy context:" In Daniel Bromley (ed.), Natural resource economics: policy problems and contemporary analysis. Boston, Massachusetts: Kluwer, Nighoff Publishing, 163-200.

Randall, Alan, John Hoehn, and David Brookshire. (1983). "Contingent valuation surveys for evaluating environmental assets," Natural Resources Journal 23, 635-648.

Simon, H. (1978). "Rationality as process and as product of thought," American Economic Review 68, 1-16.

Slovic, Paul, Baruch Fischhoff, and Sarah Lichtenstein. (1982). "Response mode, framing, and information-processing effects in risk assessment." In Robin Hogarth (ed.), New directions for methodology of social and behavioral science: Question framing and response consistency. San Francisco: Jossey-Bass, 21-36.

Slovic, Paul, Dale Griffin, and Amos Tversky. (1990). "Compatibility Effects in Judgment and Choice." In Robin M. Hogarth (ed.), Insights in Decision Making: A Tribute to Hillel J. Einhorn. Chicago, Illinois: University of Chicago Press, 5-27.

Slovic, Paul, and Sarah Lichtenstein. (1971). "Comparison of Bayesian and regression approaches to the study of information processing in judgment," Organizational Behavior and Human Performance 6, 649-744.

Slovic, Paul, Sarah Lichtenstein, and Baruch Fischhoff. (1979). "Images of disaster: Perception and acceptance of risks from nuclear power." In G. Goodman, and W. Rowe (ed.), Energy risk management. London: Academic, 223-245.

Slovic, Paul, and Douglas J. McPhillamy. (1974). "Dimensional commensurability and cue utilization in comparative judgment," Organizational Behavior and Human Performance 11, 172-194. 
Smith, V. Kerry, William Desvousges, and Ann Fisher. (1986). "A comparison of direct and indirect methods for estimating environmental benefits," American Journal of Agricultural Economics 68, 280-290.

Stevens, S. S. (1951). "Mathematics, measurement, and psychophysics." In S. S. Stevens (ed.), Handbook of Experimental Psychology. New York: Wiley, 1-49.

Tversky, Amos, and Daniel Kahneman. (1981). "The framing of decisions and the psychology of choice," Science 211, 453-458.

Tversky, Amos, Shmuel Sattath, and Paul Slovic. (1988). "Contingent weighting in judgment and choice," Psychological Review 95, 371-384.

Tversky, Amos, Paul Slovic, and Daniel Kahneman. (1990). "The causes of preference reversal," American Economic Review 80, 204-217.

Viscusi, W. Kip, and Wesley A. Magat. (1987). Learning about risk: Consumer and worker responses to hazard warnings. Cambridge: Harvard University Press.

Viscusi, W. Kip, Wesley A. Magat, and Joel Huber. (1986). "Informational regulation of consumer health risks: an empirical evaluation of hazard warnings," Rand Journal of Economics 17, 351-365.

von Winterfeldt, Detlof, and Ward Edwards. (1986). Decision analysis and behavioral research. New York: Cambridge.

Walsh, R. G., R. D. Bjonback, R. A. Aiken, and D. H. Rosenthal. (1990). "Estimating the public benefits of protecting forest quality," Journal of Environmental Management. 30, $175-189$. 


\section{ACKNOWLEDGMENTS}

The authors gratefully acknowledge the support of the Decision, Risk, and Management Science Program, National Science Foundation, through Grants SES 88-12707 and SES 90-22952 to Decision Research. We thank Ralph Keeney, Julie Irwin, John Payne, and Detlof von Winterfeldt for their insightful comments on an earlier draft of this manuscript. Any opinions, findings, and conclusions or recommendations expressed in this paper are those of the authors and do not necessarily reflect the views of the National Science Foundation. 


\section{FOOTNOTES}

1. Despite the many references in the literature to "the Contingent Valuation Method" (e.g., Mitchell \& Carson, 1989), CV is a conceptual approach which, in application, employs any variety of methods.

2. WTP techniques also are used to value human health and safety (Jones-Lee, Hammerton, \& Phillips, 1985; Viscusi \& Magat, 1987); however, this paper focuses on the evaluation of environmental resources rather than the WTP research on health and safety issues.

3. The fourth, content validity, applies only to testing situations. To assess the content validity of a typing test, for example, one would show that the test is an appropriate sample of the universe of typing skills.

4. Indeed, it has occurred to us that Fischhoff and Furby, in writing their paper, may have had an ulterior motive: to list so many requisites that the reader would realize the impossibility of achieving them without the authors' having to say so. 